\title{
Inhibiteur de protéinase à cystéine! enfin un rôle pour la lipocaline lacrymale
}

La lipocaline lacrymale, présente en quantité très importante $(30 \%$ des protéines totales) dans le film lacrymal, faisait partie de ces protéines dont la fonction jusqu'alors était inconnue. Un article récent de l'équipe d'Amerongen (Amsterdam, Pays-Bas) [1] vient de lui attribuer un rôle inattendu. Parmi les principales caractéristiques de la famille des lipocalines déjà exposées dans $m / s$ [2], retenons que ce sont des protéines essentiellement sécrétées, qui transportent des ligands hydrophobes à l'intérieur d'une cavité et possèdent un motif commun GxWY*: leur chef de file est la très connue RBP (retinol binding protein) [2]. La fonction présomptive de la lipocaline lacrymale (TL) a évolué au fur et à mesure de la mise en évidence de l'expression de son gène (LCN1) dans différents tissus: transport de rétinol vers des récepteurs potentiels de l'épithélium cornéen $[3,4]$, puis, transport des molécules sapides vers les bourgeons du goût [5], lorsqu'on a découvert que le gène de la lipocaline lacrymale était aussi exprimé dans les glandes salivaires de von Ebner. L'expression du gène, démontrée dans les cellules sécrétoires de l'épithélium trachéal et dans la prostate $[6,7]$, permettait de supposer que la lipocaline lacrymale pouvait intervenir dans la défense des épitheliums. Les lipocalines et les cystatines ont des structures tridimensionnelles différentes et n'ont en commun qu'un nombre très réduit d'acides aminés. Les cystatines (pour une revue, voir [8]) sont des protéines qui inhibent par fixation forte mais réversible une catégorie particulière de protéinases, les protéinases à cystéine

\footnotetext{
* Code à une lettre des acides aminés: A: Ala; C: Cys; $D:$ Asp; E: Glu; F: Phe; G: Gly; H: His; I: Ile; K: Lys; L:Leu; M: Met; N:Asn; P:Pro; Q: Gln;R: Arg; S: Ser; T: Thr; V: Val; W: Trp; Y: Tyr.
}

$m / s n^{\circ} 3$, vol. 13 , mars 97 (ainsi dénommées du fait de la présence d'une cystéine dans le site actif ; les plus connues sont certaines cathepsines et la papaïne). Les cystatines peuvent donc protéger les cellules de l'agression protéolytique facheuse d'agents microbiens. Les cystatines ont leur site actif situé à leur surface: il est composé (dans le cas de la cystatine $\mathrm{C}$ ) de trois domaines éloignés dans leur séquence mais proches dans l'espace du fait du repliement de la molécule: le motif QxVxG (55 à 59), très conservé, et un tryptophane en 106, sont essentiels pour l'interaction [8]. Van't Hof, examinant la séquence de la lipocaline lacrymale, a noté la présence, sur un seul fragment, à la fois de la séquence GxWY (conservée dans les lipocalines) et de la séquence $\mathrm{QxVxG}$ (conservée dans les cystatines). L'activité d'inhibiteur de protéinases à cystéine de la lipocaline lacrymale a été démontrée par sa capacité d'inhiber l'activité de la papaine [9]; l'action de la papaïne est inhibée a) par les peptides suivants: LLASDEEIQDVSG TWYLKA (séquence (3-21) pour la lipocaline lacrymale et par KLVGGAQIVAGAPWLK (séquence discontinue (55-59 et 104) pour la cystatine C ; b) par une préparation purifiée de lipocaline lacrymale pour laquelle ont été effectués les contrôles indispensables assurant qu'un contaminant à activité puissante n'a pas été co-purifié.

Un certain nombre de questions restent posées: quelle est la nature du processus conduisant, au cours de l'évolution, deux groupes de protéines sans relations structurales fortes, à remplir des fonctions similaires? Les lipocalines ont-elles plusieurs rôles? Jusqu'à présent seul leur rôle dans la régulation cellulaire avait été mis en évidence [10] et l'on peut se demander si, au cours de l'évolu- tion leur fonction a changé ou si d'autres fonctions ont été ajoutées. Le problème de la fonction de la lipocaline lacrymale semble donc résolu. Cette protéine très abondante dans le fluide lacrymal, contribue, au même titre que le lysozyme et la lactoferrine, mais avec un mécanisme d'action différent, à la protection de la cornée et de la conjonctive contre les agents bactériens.

A.M.F.G. E.L.

1. Van't Hof W, Blankenvoorde MJF, Veerman ECI, Amerongen AVN. The salivary lipocalin von Ebner's gland protein is a cysteine proteinase inhibitor. J Biol Chem 1997; 272: 1837-41.

2. Gachon AMF. Lipocalines et transport des ligands hydrophobes. Med Sci 1994; 10: 22-9.

3. Redl B, Holzfeind P, Lottspeich F. cDNA cloning and sequencing reveals human tear prealbumin to be a member of the lipophilic-ligand carrier protein superfamily. J Biol Chem 1992; 267: 20282-7.

4. Lassagne H, Ressot C, Mattei MG, Gachon AMF. Assignment of the human tear lipocalin gene (LCN1) to $9 \mathrm{q} 34$ by in situ hybridization. Genomics 1993; 18: 160-1.

5. Bläker M, Kock K, Ahlers C, Buck F, Schmale H. Molecular cloning of human von Ebner's gland protein, a member of the lipocalin superfamily highly expressed in lingual salivary glands. Biochim Biophys Acta 1993; 1172: 131-7.

6. Ressot C, Lassagne H, Kemeny JL, Gachon AMF. Tissue expression of tear lipocalin in humans. In: Sullivan DA, ed. Advances in Experimental Medicine and Biology New York: Plenum Press (sous presse). 7. Holzfeind $\mathrm{P}$, Merschak $\mathrm{P}$, Rogatsch $\mathrm{H}$, et al. Expression of the gene for tear lipocalin/von Ebner's gland protein in human prostate. FEBS Lett $1996 ; 395: 95-8$.

8 . Turk V, Bode W. The cystatins: protein inhibitors of cystein proteinases. FEBS Lett 1991; 285 : 213-9.

9. Lalmanach G, Hoebeke J, Moreau T, BrillardBourdet M, Ferrer di Martino M, Borras-Cuesta F, Gauthier F. Interaction between cystatin-derived peptides and papain. J Protein Chem 1993; 12: 23-31. 10. Flower DR. The lipocalin protein family: a role in cell regulation. FEBS Lett 1994; 354: 7-11. 